\title{
Research on the way to transform a confirmatory experiment into a comprehensive one
}

\author{
Hua Liang ${ }^{\mathrm{a}}$, Jun Bu${ }^{\mathrm{b}}$, Junmin Hua ${ }^{\mathrm{c}}$, Angeng Liu ${ }^{\mathrm{d}}$, and Lu Zhao \\ National Demonstration Center for Experimental Modern Circulation Education (Shanghai Business School), \\ No.123, Fengpu Avenue, Fengxian District, Shanghai, 201400, People's Republic of China \\ a21180001@sbs.edu.cn, ${ }^{\text {b221090016@sbs.edu.cn, chuajunmin@sina.com, }{ }^{d} 22090471 @ s b s . e d u . c n,{ }^{e} 22170025}$ \\ @sbs.edu.cn
}

Keywords: Confirmatory experiment; Comprehensive experiment; one-shot game; repeated game; Nash equilibrium

\begin{abstract}
Gaming tools are effective teaching aids to supplement conventional teaching techniques, and a flexible game environment have been developed in the literature. Based on the marketing game, a confirmatory experiment is designed to test the Nash equilibrium of prisoners' dilemma game. In order to integrate more knowledge within one experiment and improve teaching effectiveness, the confirmatory experiment is transformed into a comprehensive one by repeating the marketing game 30 times. In the first round only 3 pairs of students play (advertising, advertising), which is the Nash equilibrium of the one-shot game. The result suggests that it is not a good way to design comprehensive experiments by integrating different game scenarios into one experiment. Alternatively, problem-based learning with multiple-disciplined methods can be employed to construct effective comprehensive experiments.
\end{abstract}

\section{Introduction}

In industry, most enterprises prefer to recruit people who have multi-functional abilities in order to increase their market competitiveness. In the field of higher education, most universities are under sustained pressure to decrease instructional costs. As a result, instructors are facing the challenge of motivating students with real-life scenarios in which several subjects are integrated within one course. They have to continuously develop and adopt novel pedagogical methods to improve teaching effectiveness. For experimental courses, gaming tools have been proved to be effective teaching aids to supplement conventional teaching techniques [1,2,3].

A game is a goal-directed, challenging, and competitive activity that is conducted within a framework of agreed rules to provide a playful learning environment [4,5,6,7]. Instructors have successfully applied games in class in recent years while teaching decision science courses such as production management, logistic management, and supply chain management $[5,6,8]$. Usually, the instructor designs the game, and the students act as the players. The first and best known production/logistics game is MIT Beer Game, which was originally developed by the Massachusetts Institute of Technology in the 1960s. Columbia university developed Columbia Beer Game in 1999, and the University of Haifa developed Hulia Beer Game in 2000. These three Beer Games all exhibit beer production and distribution in a multi-stage distribution channel, and players act as a manufacturer, distributor, wholesaler, or retailer to determine production or ordering quantities. In addition, Swedish Institute of Computer Science developed Trading Agent Competition Game to present online bidding on multiple markets simultaneously, and players act as an agent to manufacture PCs, win customer orders, and procure components; Stanford University developed Littlefield Technology Game to give a manufacturing simulation in made-to-order assembler of electronic systems, and players act as a manufacturer to determine utilization, queuing, scheduling and inventory; Technical University of Denmark developed Logi game to simulate material flows in a distribution channel for bicycle industry, and players act as a manufacturer, wholesaler, or retailer to 
make manufacturing and inventory decisions; Georgia Institute of Technology developed Supply Chain Game to provide a production and distribution simulation in automobile industry, and players act as a decision-maker in a competitive supply chain framework, such as a manufacturer, transporter, assembler and supplier.

One lesson learned from applying games in teaching is the requirement of adopting different types of games. Given that students play different roles in different courses, no single game can be successfully applied to all learning situations, and various games with different rules have to be designed for different courses [9,10,11]. Every time instructors adopt games to assist in teaching, they require a particular game based on the need of a single course [12]. As a result, too many rules have to be prepared by instructors and learned by students, which threaten instructors' willingness to adopt game-assisted instruction. To address this problem, Chang et al. have developed a flexible web-based object-oriented game environment that simulates various decision-making scenarios that often are observed in production, logistics, and supply chain management [13].

However, are the experimental courses with games effective? What's the challenge that instructors are confronted with? The research on these question is scarce. Games are often applied in confirmatory instead of comprehensive experiments. For example, Beer Game are often employed to test how people's decision patterns in production, logistics and customer chains produce unexpected and undesired results. In fact, the existing literature on simulation games for production and logistics management pays much attention to helping students gain an understanding of real industries rather than prepare for their professional careers. This paper will attempt to fill the gap. The objective of this study is to provide a common fundamental infrastructure for effective comprehensive experiments. The questions are: (1) what's the difference between confirmatory experiments and comprehensive ones? (2) how should instructors guide the interaction among students who serve as players in games? The contribution of this study includes: (1) it develops feasible methods to guide competition and collaboration between players in simulation games; (2) it provides a multi-disciplined way to transform confirmatory experiments into comprehensive ones; (3) it constructs a common fundamental infrastructure for effective comprehensive experiments. According to Chinese index system for qualification evaluation of undergraduate teaching, every regular institution of higher education must offer some courses of comprehensive experiments [14]. So it's very important for instructors to apply gaming tools more skillfully.

The rest of the paper is organized as follows. The second section presents a game scenario observed in logistics marketing. The third section describes the failure in the experiment transformation with the marketing game. The fourth section proposes a multi-disciplined way to transform the confirmatory experiment into a comprehensive one, and discusses a common fundamental infrastructure for effective comprehensive experiments. The sixth section provides conclusions and implications.

\section{Game in logistics marketing}

The following is a game scenario of marketing that is observed in logistics industry. Logistics enterprises A and B provide similar logistics service. Each percent of market share yields a net payoff of 1 . Without advertising both firms have $50 \%$ of the market. The cost of advertising is equal to 10 but leads to an increase in market share of $20 \%$ at the expense of the other enterprise. The enterprises make their advertising decisions simultaneously and independently. The total market for logistics service is of fixed size. This game can be represented by payoff bimatrix (1).

$$
\begin{array}{ccc} 
& \multicolumn{2}{c}{\begin{array}{c}
\text { enterprise B } \\
\text { not advertising advertising }
\end{array}} \\
\text { enterprise A not advertising } & \left(\begin{array}{ll}
50,50 & 30,60 \\
60,30 & 40,40
\end{array}\right)
\end{array} \text { advertising } .
$$

In this prisoners' dilemma game, for both enterprises advertising is a strictly dominant choice: for 
each party, advertising is (strictly) the best choice, whatever the other party does. It is natural to argue that (advertising, advertising) is the unique Nash equilibrium of the one-shot game, also if mixed strategies are allowed. The outcome of this game will be the pair of choices (advertising, advertising), leading to the payoffs $(40,40)$, that are inferior and not Pareto optimal. These two logistics enterprises could obtain the higher payoff of 50 for each by both playing not advertising.

\section{Failure in experiment transformation}

Based on the marketing game, a confirmatory experiment is designed to test the Nash equilibrium of one-shot game. It is applied in an experimental course titled Experiential Simulation Practice on the Practical work of Modern Logistics in Shanghai Business School. Active Server Pages technology is used to create dynamic web content. The web pages are constructed by html codes embedded with VB script. When a client sends a request to the game server through ASP web page, the request is sent by the ASP program and executed through VB script. As a result, the corresponding response is then transmitted back to the client from the game server. The information and data that exchanged between client and game server are based on Hyper Text Transfer Protocol (HTTP). A database of Microsoft SQL Server 2014 (Enterprise Edition, x64) is employed to record all game history, which can be connected through JDBC driver to retrieve data for post-game analysis. 30 Students are randomly divided into pairs of two, and play the marketing game respectively: one acts as enterprise A, the other plays the role of enterprise B. Everyone plays the marketing game from any web browsers connecting to the game server.

In order to integrate more knowledge within one experiment and improve teaching effectiveness, the confirmatory experiment can be transformed into a comprehensive one by repeating the marketing game 30 times. For the purpose of motivating the students to play the game earnestly, their payoffs are linked with their scores of the experiment. The first round of game is regarded as a one-shot game, and the corresponding payoff determines $50 \%$ of the total score of every student. The 30 rounds of games are regarded as a repeated game, and the average payoff determines the rest $50 \%$ of the total score of every student. As shown in Table 1, in the first round only 3 pairs of students play (advertising, advertising), which is the Nash equilibrium of the one-shot game. In the sense of testing the Nash equilibrium of one-shot game, the experiment transformation is failing, which is mainly due to the repeat of the game.

In fact, if the marketing game is repeated an infinite number of times, each pair of students would play some Nash equilibrium of the repeated game in the first 30 rounds. By playing appropriate sequences of elements from the set of possible outcomes (not advertising, not advertising), (not advertising, advertising), (advertising, not advertising), (advertising, advertising) $\}$ of the marketing one-shot game, the students can on average reach any convex combination of the associated payoffs in the long run. That is, take any such combination $\alpha_{1}(50,50)+\alpha_{2}(30,60)+\alpha_{3}(60,30)+\alpha_{4}(40,40)$, where $\alpha_{i} \in R, \alpha_{i} \geq 0$ for every $i=1,2,3,4$ and $\alpha_{1}+\alpha_{2}+\alpha_{3}+\alpha_{4}=1$. By choosing a sequence of possible outcomes such that (not advertising, not advertising) occurs in the long run in a fraction $\alpha_{1}$ of the stages, (not advertising, advertising) in a fraction $\alpha_{2}$, (advertising, not advertising) in a fraction $\alpha_{3}$, (advertising, advertising) in a fraction $\alpha_{4}$, then the above payoffs are reached as averages in the limit. As long as these limiting average payoffs exceed 40 for each student, associated trigger strategies can be formulated that lead to these payoffs and that trigger eternal play of (advertising, advertising) after a deviation. For a common discount factor sufficiently high, such strategies form a subgame perfect equilibrium. As shown in Fig. 1, for every payoff pair in the shaded area there is a common discount factor large enough such that this payoff pair can be obtained as the limiting average in a subgame perfect equilibrium. 
Table 1 Results of the confirmatory experiment

\begin{tabular}{|c|c|c|c|}
\hline Outcomes of the games & $\begin{array}{c}\text { (not advertising, } \\
\text { not advertising) }\end{array}$ & $\begin{array}{c}\text { (not advertising, advertising) } \\
\text { or (advertising, not } \\
\text { advertising) }\end{array}$ & $\begin{array}{c}\text { (advertising } \\
\text {, adverting) }\end{array}$ \\
\hline $\begin{array}{c}\text { Number of students in the first } \\
\text { round [pair] }\end{array}$ & 7 & 5 & 3 \\
\hline $\begin{array}{c}\text { Number of students in the } \\
\text { thirtieth round [pair] }\end{array}$ & 8 & 3 & 4 \\
\hline
\end{tabular}

$(30,60)$

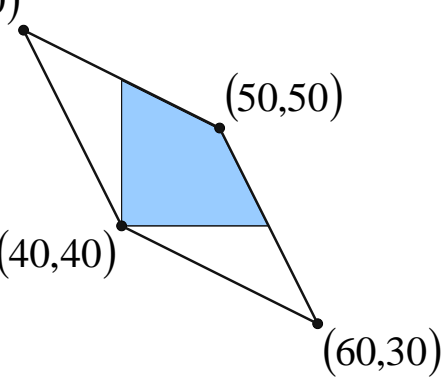

Fig. 1 limiting average payoffs in a subgame perfect equilibrium

\section{Discussion on a common infrastructure}

By and large, There are four kinds of experimental courses. Demonstrative experiments refer to the teaching process through instructor's demonstration to help students to understand the objective things, learn their form, structure, interrelation, the process and law of change. Confirmatory experiments refer to the teaching process through students' phenomena observation, data record, calculation and analysis of specific experiment to help them master the method and skill of the experiment, test some principle, theory and conclusion, and deepen their understanding of what they have learned. Comprehensive experiments refer to the teaching process through students' operation of the experiment involving comprehensive knowledge of one or more courses. Designing experiments refer to the teaching process through students' designing and realizing the experiment plan according to the purpose, requirement and condition of the experiment provided by the instructor.

The difference between confirmatory experiments and comprehensive ones is summed up as that the former involves more knowledge than the latter. The marketing one-shot game is regarded a confirmatory experiment. The interaction between the players is competition rather than collaboration, and both of them would play advertising. The confirmatory experiment can be employed to test the unique Nash equilibrium of prisoners' dilemma game. After the marketing game is repeated many times, a confirmatory experiment is transformed into a comprehensive one. The interaction between the players involves collaboration besides competition. The players 'tacitly' agree on a certain sequence of play, but revert to playing advertising forever after a deviation. The comprehensive experiment cannot be used to test the unique Nash equilibrium of prisoners' dilemma game.

Although a flexible game environment has been developed in the literature, it is not a good way to design comprehensive experiments by integrating different game scenarios into one experiment. As a substitute way, Problem-based learning (PBL) is a student-centered pedagogy in which students learn about a subject through the experience of solving an open-ended problem found in trigger material. The PBL process does not focus on problem solving with a defined solution, but it allows for the development of other desirable skills and attributes. This includes knowledge acquisition, enhanced group collaboration and communication. The PBL process was developed for medical education and has since been broadened in applications for other programs of learning. The process allows for learners to develop skills used for their future practice. 
For the marketing game, the problem is how the players get more information about the counterpart in order to collaborate with each other and agree on a certain sequence of play as soon as possible. The problem may be solved by multiple-disciplined methods. From the perspective of psychology, the instructor can first test the personality factors of all students, and then provide every student with the test report of his counterpart when he plays the game. For example, the Sixteen Personality Factor Questionnaire (16PF) is a self-report personality test developed over several decades of empirical research by Raymond B. Cattell, Maurice Tatsuoka and Herbert Eber. The 16PF provides a measure of normal personality and can also be used by psychologists, and other mental health professionals, as a clinical instrument to help diagnose psychiatric disorders, as well as help with prognosis and therapy planning. The 16PF instrument provides clinicians with a normal-range measurement of anxiety, adjustment, emotional stability and behavioral problems. It can also be used within other areas of psychology, such as career and occupational selection. From the perspective of econometrics, every student may analyze the game history of the counterpart with regression methods to predict what strategy the counterpart will play in the next round of game.

\section{Conclusions}

(1) The Nash equilibrium of repeated marketing game is different from that of one-shot marketing game. In one-shot marketing game, each player playing his dominant action advertising, and the Nash equilibrium is a Pareto inferior outcome. In repeated marketing game, this bad outcome can be avoided at a price of the embarrassment of richness, i.e. the existence of a multitude of outcomes attainable in equilibrium.

(2) It is not a good way to design comprehensive experiments by integrating different game scenarios into one experiment. A one-shot marketing game can be employ to test the Nash equilibrium of prisoners' dilemma game. When the marketing game is repeated, it cannot test the Nash equilibrium of prisoners' dilemma game successfully.

(3) Problem-based learning with multiple-disciplined methods is a better way to construct comprehensive experiments. Both the test of personality factor test and the regression of game history can be employed to predict what strategy the counterpart will play in the next round of game.

\section{Acknowledgements}

This work was financially supported by the Project of Teaching Reform Research on General Experimental Business Courses for Business Literacy Education of Shanghai Business School in 2018 (Project title: Teaching reform research on problem-based experiential courses of modern logistics).

\section{References}

[1] J.M. Randel, B.A. Morris, C.D. Wetzel and B.V. Whitehill: Simulation and Gaming Vol 23 (1992), pp. 261-275.

[2] R. Caillois: Men Play and Games (University of Illinois Press, Urbana 2001)

[3] T. Lainema and S. Nurmi: Computers and Education Vol 47 (2006), pp. 94-115.

[4] T.W. Malone: Cognitive Science Vol 4 (1981), pp. 333-369.

[5] S.M. Alessi and S.R. Trollip: Computer-based Instruction, Methods and Development (Prentice-Hall, New Jersey 1985).

[6] J.J. Martocchio and J. Webster: Personnel Psychology Vol. 45 (1992), pp. 553-578.

[7] J.V. Dempsey, B. Lucassen, L. Haynes and M. Casey: Instructional applications of computer games (Technical Report ED394500, University of South Alabama 1996). 
[8] C.N. Quinn: Education and Information Technologies Vol. 1 (1996), pp. 251-269.

[9] R.G. Graham and C.F. Gray: Business Games Handbook (American Management Association, 1969).

[10] C. Elgood: Handbook of Management Games and Simulation, sixth ed. (Gower Publishing, Aldershot 1997).

[11] M.A. Lewis and H.R. Maylor: International Journal of Production Economics Vol 105 (2007), pp. 134-149.

[12] J.O. Riis: Games for production management (A Special Interest Group under the IFIP Working Group 5.7 on Integrated Production Management, 1999).

[13] Y.C. Chng, W.C. Chen, Y.N. Yang and H.C. Chao: Simulation Modelling Practice and Theory Vol 17 (2009), pp. 1241-1253.

[14] Information on http://www.moe.gov.cn/srcsite/A08/s7056/201802/t20180208_327138.html 